Published in final edited form as:

Chembiochem. 2018 February 02; 19(3): 203-206. doi:10.1002/cbic.201700626.

\title{
Alphanumerical Visual Display Made of DNA Logic Gates for Drug Susceptibility Testing of Pathogens
}

\author{
Ryan P. Connelly, Dr. Evgeny S. Morozkin, and Dr. Yulia V. Gerasimova \\ Chemistry Department, University of Central Florida 4111 Libra Drive, Orlando, FL 32816 (USA)
}

\begin{abstract}
Molecular diagnostics of drug-resistant pathogens require the analysis of point mutations in bacterial or viral genomes, which is usually performed by trained professionals and/or by sophisticated computer algorithms. We have developed a DNA-based logic system that autonomously analyzes mutations found in the genome of Mycobacterium tuberculosis complex (MTC) bacteria and communicates the output to a human user as alphanumeric characters read by the naked eye. The five-gate system displays "O" ("no infection") for the absence of MTC infection and "P" or "F" for passing or failing a drug-susceptibility test, respectively.
\end{abstract}

\section{Keywords}

DNA logic gates; G-quadruplexes; rifampin susceptibility; peroxidases; deoxyribozymes

\begin{abstract}
Devices that use individual molecules as computational elements have being under experimental validation since 1993. ${ }^{[1]}$ DNA-based biocomputing devices are promising for the analysis of nucleic acids. ${ }^{[2]}$ However, to the best of our knowledge, there is no broadscale use of molecular computers or logic circuits. At the same time, biomedical diagnosis still relies on the manual or electronic computer-based analysis of outputs from simple digital sensors with a YES (digital 1) or NO (digital 0) response. We hypothesize that analyses could be performed by molecular logic circuits/processors that provide a userfriendly output. This study is devoted to the development of such an output/interface. The alphanumerical display reported here takes advantage of logic circuits made of DNA to simplify medical diagnostics, thus making it accessible to a general user. We demonstrate the ability of the DNA logic circuits to perform sophisticated analysis of point mutations at room temperature. One key advantage of the system is the improvement in reliability conferred by the analysis of each analyte by several sensors, as detailed below. The display produces a user-friendly visible output that can be read by the naked eye.

In this proof-of-concept study, we report the design of an array of DNA logic gates that produce an alphanumerical character as an output, and the array's implementation in
\end{abstract}

Correspondence to: Yulia V. Gerasimova.

Conflict of Interest

The authors declare no conflict of interest.

Supporting information and the ORCID identification numbers for the authors of this article can be found under https://doi.org/ 10.1002/cbic.201700626. 
detecting Mycobacterium tuberculosis complex (MTC) and analyzing the drug susceptibility of the bacteria. MTC is a group of bacteria that are the causative agent of tuberculosis (TB). The treatment of TB is complicated by the development of resistance to one or several drugs. ${ }^{[4]}$ Rifampin (RIF) is a first-line anti-tubercular agent targeting bacterial RNA polymerase. Point mutations in an 81-bp "hot spot" region (aa 507-533) of the $r p o B$ gene are known to render MTC resistant to RIF. The most prevalent point mutation causing drug resistance is a single-nucleotide substitution (SNS) at codon 526. ${ }^{[5]}$ Therefore, in this study, we tailored DNA logic gates to respond to DNA inputs $\mathrm{RIF}^{\mathrm{S}}$ and $\mathrm{RIF}^{\mathrm{R}}$, which correspond to a fragment of the $r p o B$ gene-containing codon 526 from RIF-susceptible and RIF-resistant MTC, respectively (Table $\mathrm{S} 1$ in the Supporting Information).

The logic gates were arranged into a 305 display that would produce an alphanumerical character: the letter "O" in the case of a no-TB outcome, the letter "P" if the test for RIF susceptibility passed or "F" if it failed (Figure 1A, left). To achieve this pattern, the wells $d 3$, $e 2$, and $e 3$ should stay colorless when samples are TB-positive; well $c 2$ should turn $\mathrm{ON}$ in response to either RIF-sensitive or RIF-resistant MTC; and wells $b 3$ and $c 3$ needed to turn OFF only in the case of the RIF-resistant bacteria (Figure 1B). Wells a1, a2, a3, b1, c1, d1, and $e 1$ of the display should remain colored, while wells $b 2$ and $d 2$ should stay colorless regardless of the presence or absence of TB. This display set up required the following logic gates: OR; NOR, and $\mathrm{NOT}^{\mathrm{R}}$, with the truth tables as shown in Figure 1C, as well as PASS 1 and PASS 0 , the logical behavior of which is described below.

As a PASS 1 logic gate, which produces a high signal (digital output 1) regardless of the presence of a DNA input, we used a peroxidase-like deoxyribozyme, PW17. ${ }^{[6]}$ This G-rich DNA oligomer forms a G-quadruplex $\left(\mathrm{G}_{4}\right)$ structure stabilized by cations, such as $\mathrm{K}^{+}$ (Scheme 1A, left). ${ }^{[6]}$ In the presence of hemin, PW17 demonstrates a catalytic activity for peroxidation of a colorless organic compound (e.g., 2,2'-azino-bis(3-ethylbenzothiazoline-6-sulfonic acid), ABTS) into a colored product (Scheme $1 \mathrm{~A}$, right). The catalytic activity of PW17 does not depend on the presence of $\mathrm{RIF}^{\mathrm{S}}$ or RIF $^{\mathrm{R}}$, therefore the wells containing PW17 are colored both in the presence and in the absence of inputs. The lack of PW17, or any other DNA logic-gate strands, results in PASS 0 logic - a low output (absence of color) would be detected regardless of input.

The signal-generating modules of the other DNA logic gates designed in this study were based on PW17. For this purpose, the deoxyribozyme sequence was split into two subunits (strands A and B), each of which contained two of the four G-triplets of PW17. Each subunit was elongated with the sequence constituting a communicating module that contained the input-recognition site. Association of strands A and B formed the catalytically active $\mathrm{G}_{4}$ peroxidase, generating a green color (high output). Using this "split" approach, ${ }^{[7]}$ we designed $\mathrm{YES}^{\mathrm{S}}$ and OR gates (Scheme $1 \mathrm{~B}$ ), which turned on in response to input(s). In contrast, for a NOR gate, the addition of input(s) resulted in dissociation of the $\mathrm{G}_{4}$ structure (Scheme $1 \mathrm{C}$ ).

The input-recognition site of a two-input $\mathrm{G}_{4}$-OR gate was complementary to the 31 -nt $5^{\prime}$ terminal fragment of $\mathrm{RIF}^{\mathrm{S}}$ and $\mathrm{RIF}^{\mathrm{R}}$, which is identical in both inputs (Figure S1A, Table S1). Therefore, high output was expected in the presence of either $\operatorname{RIF}^{S}$ or $\mathrm{RIF}^{\mathrm{R}}$, but not in 
their absence (Scheme 1 A). The proper logical behavior of the individual gate was achieved with a clear difference in color intensity between the absence and the presence of either $\mathrm{RIF}^{\mathrm{S}}$ or RIF ${ }^{\mathrm{R}}$ input (Figure S1 B). Formation of the high-output DNA complex (OR-A/OR$\mathrm{B}$ /input) was also demonstrated by the appearance of a low-mobility band in a native polyacrylamide gel (Figure S1 C).

The $\mathrm{G}_{4}-\mathrm{YES}^{\mathrm{S}}$ gate computing the identity function of $\mathrm{RIF}^{\mathrm{S}}$ input was designed in a similar way to the $\mathrm{G}_{4}$-OR gate. The only difference was in the input-recognition site of the gate; it was complementary to a 28 -nt fragment in the middle of the input sequence containing a $\mathrm{C}$ $>\mathrm{T}$ substitution in $\mathrm{RIF}^{\mathrm{R}}$ input (Figure $\mathrm{S} 2 \mathrm{~A}$ ). The $\mathrm{YES}^{\mathrm{S}}$-B strand was chosen to have a short (8-nt) $\mathrm{RIF}^{\mathrm{S}}$-recognition region in order to prevent its binding to the SNS-containing $\mathrm{RIF}^{\mathrm{R}}$ input. $\mathrm{YES}^{\mathrm{S}}$-A strand was designed to be long enough to promote efficient binding of the $\mathrm{RIF}^{S}$ input to the gate. This feature of the strand enabled it to bind $\mathrm{RIF}^{\mathrm{R}}$ as well (Figure S2 B). At the same time, the combination of long $\mathrm{YES}^{\mathrm{S}}$-A with short $\mathrm{YES}^{\mathrm{S}}$-B prevented efficient association of YES $^{S}-\mathrm{A} / \mathrm{YES}^{\mathrm{S}}-\mathrm{B} / \mathrm{RIF}^{\mathrm{R}}$, thus ensuring a low output in response to $\mathrm{RIF}^{\mathrm{R}}$. We also introduced a G15A substitution in the input-recognition domain of YES $\mathrm{S}^{\mathrm{S}} \mathrm{A}$ to sequester any $\mathrm{G}_{4}$-forming fragments into a stable stem structure in its dissociated state (Figure S2, compare structures in panels A and C); this helped to minimize background signal. Overall, the formation of a high-input complex and the proper digital behavior of $\mathrm{YES}^{\mathrm{S}}$ gate were observed, as expected, only in the presence of $\mathrm{RIF}^{\mathrm{S}}$, but not $\mathrm{RIF}^{\mathrm{R}}$ (Figure S2 D and E).

The $\mathrm{G}_{4}$-NOR gate was designed to exhibit high signal only in the absence of inputs; the presence of either $\mathrm{RIF}^{\mathrm{S}}$ or $\mathrm{RIF}^{\mathrm{R}}$ would destabilize the $\mathrm{G}_{4}$ structure and result in a low output (Figure $1 \mathrm{C}$ and Scheme $1 \mathrm{~A}$ ). The NOR-B strand contained a $5^{\prime}$-terminal domain complementary to the $3^{\prime}$-terminal part of the NOR-A strand in order to enable association of the strands into a catalytically active $\mathrm{G}_{4}$ structure in the absence of inputs (Figure $\mathrm{S} 3 \mathrm{~A}$ ). At the same time, the $3^{\prime}$-end of the NOR-A strand contained the input-recognition site, with the first $4 \mathrm{nt}$ being complementary only to the input sequence, but not to NOR-B. This 4-nt fragment served as a "toehold" for input-mediated displacement of NOR-A from the NORA-NOR-B complex, which turned the gate off. As expected, because NOR-A bound to the input outside the mutation site, the gate did not discriminate between $\mathrm{RIF}^{\mathrm{S}}$ and RIF $^{\mathrm{R}}$ (Figure S3 B). The formation of the NOR-A-NOR-B complex in the absence of inputs, as well as the NOR-A/Input complex in the presence of either $\mathrm{RIF}^{\mathrm{S}}$ or $\mathrm{RIF}^{\mathrm{R}}$ was confirmed by gel electrophoresis (Figure S3 C).

Finally, we mixed YES ${ }^{\mathrm{S}}$ and NOR gates to obtain the $\mathrm{NOT}^{\mathrm{R}}$ logic function (Figure S4 A) the presence of $\mathrm{RIF}^{\mathrm{R}}$ input (binary input 1) resulted in low output (absence of color), whereas high output was observed either without the inputs or in the presence of RIF $S$ (Scheme $1 \mathrm{~A}$ ). YES ${ }^{\mathrm{S}}$ and NOR gates competed for the input but otherwise did not interfere with each other, as can be seen by the proper pattern of color development and by gel analysis (Figure S4 B and C). It should be noted that the ability of the display to differentiate between $\mathrm{RIF}^{\mathrm{S}}$ and $\mathrm{RIF}^{\mathrm{R}}$ inputs relies on the specificity of the NOT ${ }^{\mathrm{R}}$ logic function. It was demonstrated that $\mathrm{RIF}^{\mathrm{R}}$ input triggered a two- to threefold increase in absorbance compared to the response to $\mathrm{RIF}^{\mathrm{S}}$ input; this enabled reliable discrimination of inputs even by the naked eye (Figure S4 C). 
The high-output signal for the YES ${ }^{\mathrm{S}}$, OR, and NOR gates was generated within the first 10 min after the addition of hydrogen peroxide and was stable at least for 60 min (Figure S5). An input concentration equimolar to the concentration of the gate strands yielded a signal maximum, as expected. For the NOR gate, the signal plateaued at an $\mathrm{RIF}^{\mathrm{S}}$ concentration of $0.5-2 \mu \mathrm{M}$, whereas for the $\mathrm{YES}^{\mathrm{S}}$ and OR gates, the signal decreased when RIFS was in excess over the gate strand, due to a heightened probability of forming catalytically inactive complexes between the input strand and one of the gate strands. As little as 30-70 nM of $\mathrm{RIF}^{\mathrm{S}}$ was sufficient to statistically differentiate between the low- and high-output states of the YES ${ }^{\mathrm{S}}$, OR, and NOR gates. Visual differentiation can be achieved at an input concentration of $0.2-0.5 \mu \mathrm{M}$, which can be attained after isothermal amplification of the pathogen nucleic acid (e.g., by using LAMP, RPA, NASBA).

Having confirmed the proper digital behavior of all $\mathrm{G}_{4}$ gates, we arranged the five gates into a 305 display (Figure 1B). The array wells developed color over the course of analysis. The correct pattern of colored wells in the presence of either $\mathrm{RIF}^{\mathrm{S}}$ or $\mathrm{RIF}^{\mathrm{R}}$ input, or in the absence of any MTC-specific input, was experimentally observed with no instrument required to read the display output (Figure $1 \mathrm{~A}$, right). In addition to $\mathrm{RIF}^{\mathrm{R}}$ input, which corresponded to CAC > TAC substitution in $r p o B$ codon 526, we tested the response of the display to input $\mathrm{RIF}^{\mathrm{R}}-\mathrm{G}$ (Table $\mathrm{S} 1$ ), an analogue of $\mathrm{RIF}^{\mathrm{R}}$ containing the $\mathrm{CAC}>\mathrm{GAC}$ substitution, which is known to be the second most prevalent drug-resistance-causing point mutation in $r p o B$ codon 526. ${ }^{[5]}$ The stable secondary structure of this input (Figure S5 A) was a constraint on its hybridization to the input-recognition region of the OR gate. This resulted in a weaker response of the $\mathrm{G}_{4}-\mathrm{OR}$ gate to $\mathrm{RIF}^{\mathrm{R}}-\mathrm{G}$ than to the other two inputs (Figure S1 B). Despite this constraint, the display output triggered by the presence of $\mathrm{RIF}^{\mathrm{R}_{-}}$ G could be unambiguously read as "F", indicating a RIF-resistant phenotype. This highlights the advantage of logic-gate-based display sensors: several logic units acting in parallel on a given input allow for unequivocal target classification. A similar principle is used in DNA microarrays, in which multiple probes differing by one or two nucleotides interrogate the same target sequence to improve the reliability of the test. ${ }^{[8]}$

The power of multiple individualized reactions for the analysis of virus signature sequences has been recently demonstrated by using a fluorescent display made of deoxyribozymebased logic gates. ${ }^{[2 \mathrm{a}, \mathrm{h}]}$ The presence of a particular virus-related input was read as the first letter of the virus name upon visualization of the fluorescent read-out with a UV-light box after overnight incubation. In our work, the displayed character can be read by the naked eye almost immediately after addition of the input. This is achieved by the use of the peroxidaselike de-oxyribozyme PW17, which meditates color change. The split design of the logic gates enabled high selectivity towards point mutations even at room temperature, according to the concept that we developed earlier. ${ }^{[9]}$ This differentiation power capability of the logic gate allowed input to be classified according to MTC RIF-susceptibility genotype.

Moreover, the multi-stranded design of DNA logic gates enabled the gate performance to be fine-tuned by independent optimization of the design and concentration of each strand. ${ }^{[10]}$ For example, having long input-recognition regions of one or both strands allowed efficient hybridization, even to folded inputs with stable secondary structures. ${ }^{[11]}$ Constructs with different splitting modes that reconstitute into active $\mathrm{G}_{4}$ peroxidase were reported earlier; ${ }^{[10]}$ for example, a PW17-based probe with the $\mathrm{G}_{4}$-forming sequence split asymmetrically (i.e. 
one strand containing three G-triplets and the other having one G-triplet) was used to detect point mutations in the $r p o B$ gene of rifampin-resistant $M$. tuberculosis. ${ }^{[10 b]}$ In this case, reliable differentiation between the wild-type- and point-mutation-containing analytes was possible only upon addition of a competition probe that sequestered the mismatched analyte, thereby preventing its binding to the PW17-based probe. The use of several logic constructs responding to the same input sequence, as reported in our work, not only differentiates point mutations, but also provides a user-friendly readout.

In conclusion, we have developed an array of DNA logic gates based on $\mathrm{G}_{4}$ peroxidase that displays a specific alphanumerical character in accordance with the sequence of a pathogenrelated DNA input. Importantly, the display did not require any instrumentation for the character read-out, which could be done with the naked eye merely minutes after the input had been added. In this proof-of-concept work, the logic gates of the display responded to a fragment of the $M$. tuberculosis complex $r p o B$ gene to unambiguously distinguish the absence of the input from the presence of either wild-type (classified as RIF-sensitive bacterial phenotype) or SNS-containing input (classified as RIF-resistant phenotype). Each analyte was interrogated by several gates $\left(\mathrm{YES}^{\mathrm{S}}\right.$, OR, NOR), thus increasing the reliability of detection. Even though this proof-of concept study reports preliminary results, it highlights the advantages of logic-gate-based "intelligent" sensing devices for autonomous and less ambiguous detection of infectious diseases, which contributes to the repertoire of instrument-free molecular-graphics processing units and could stimulate their industrial uses.

\section{Experimental Section}

DNA oligonucleotides were purchased from IDT, Inc. (Cornville, IA, USA) and used without purification. Hemin, ABTS and $\mathrm{H}_{2} \mathrm{O}_{2}$ were purchased from Sigma-Aldrich. For a visual (colorimetric) assay, samples containing strands of DNA logic gates $(0.5 \mu \mathrm{M}$ for NOR gate and $1 \mu \mathrm{M}$ for YES ${ }^{S}$ and OR gates) were mixed with DNA inputs $(1 \mu \mathrm{M})$ in a colorimetric buffer (50 mM HEPES.NaOH, pH 7.4, $50 \mathrm{mM} \mathrm{MgCl}_{2}, 20 \mathrm{mM} \mathrm{KCl}, 120 \mathrm{mM}$ $\mathrm{NaCl}, 1 \% \mathrm{DMSO}$, and $0.03 \%$ Triton $\mathrm{X}-100)$ at room temperature followed by the addition of ABTS $(1 \mathrm{mM})$, hemin $(0.375 \mu \mathrm{M})$ and $\mathrm{H}_{2} \mathrm{O}_{2}(1 \mathrm{mM})$; a blue-green color developed. For quantification purposes, the absorbance of the samples at $420 \mathrm{~nm}$ was measured on a Thermo Scientific NanoDrop OneC UV/Vis Spectrophotometer. For gel electrophoresis analysis of low- and high-output complexes of the gates, the samples containing gate strands in the absence or presence of inputs were mixed at the concentrations used for the assay, loaded onto 12 or $15 \%$ polyacrylamide gels supplemented with $\mathrm{MgCl}_{2}(10 \mathrm{mM})$ and $\mathrm{KCl}$ $(10 \mathrm{mM})$, and the gels were run for $2 \mathrm{~h}$ at $80 \mathrm{~V}$. Alphanumerical display was made by pipetting the DNA logic gate strands into designated positions of a well plate, each of which contained the colorimetric buffer and one of the inputs. The character corresponding to the input sequence was observed upon addition of hemin, ABTS and $\mathrm{H}_{2} \mathrm{O}_{2}$.

\section{Supplementary Material}

Refer to Web version on PubMed Central for supplementary material. 


\section{Acknowledgments}

Research reported in this publication was supported by National Institute of Allergy and Infectious Diseases of the National Institutes of Health under award number R21AI123876. The content is solely the responsibility of the authors and does not necessarily represent the official views of the National Institutes of Health.

\section{References}

1. De Silva AP, Gunaratne HQN, McCoy CP. Nature. 1993; 364:42-44.

2. a) Cornett EM, Campbell EA, Gulenay G, Peterson E, Bhaskar N, Kolpashchikov DM. Angew Chem Int Ed. 2012; 51:9075-9077.Angew Chem. 2012; 124:9209-9211.b) Poje JE, Kastratovic T, Macdonald AR, Guillermo AC, Troetti SE, Jabado OJ, Fanning ML, Stephanovic D, Macdonald J. Angew Chem Int Ed. 2014; 53:9222-9225.Angew Chem. 2014; 126:9376-9379.c) Lai YH, Sun SC, Chuang MC. Biosensors. 2014; 4:273-300. [PubMed: 25587423] d) Gerasimova YV, Kolpashchikov DM. Chem Commun. 2015; 51:870-872.e) Chen Y, Song Y, Wu F, Liu W, Fu B, Feng B, Zhou X. Chem Commun. 2015; 51:6980-6983.f) Bi S, Ye J, Dong Y, Li H, Cao W. Chem Commun. 2016; 52:402-405.g) Ge L, Wang W, Sun X, Hou T, Li F. Anal Chem. 2016; 88:96919698. [PubMed: 27582358] h) Dobrin A, Saxena P, Fussenegger M. Integr Biol. 2016; 8:409-430.i) Vijayakumar P, Macdonald J. ChemPhysChem. 2017; 18:1735-1741. [PubMed: 28342196]

3. May, EE., Harper, JC., Brozik, SM. Modeling, Methodologies and Tools for Molecular and Nanoscale Communications. Suzuki, J.Nakano, T., Moore, MJ., editors. Springer International Publishing; 2017. p. 541-577.

4. a) Ahmad S, Mokaddas E. Respir Med. 2009; 103:1777-1790. [PubMed: 19660927] b) Chiang CY, Centis R, Migliori GB. Respirology. 2010; 15:413-432. [PubMed: 20337989]

5. a) Musser JM. Clin Microbiol Rev. 1995; 8:496-514. [PubMed: 8665467] b) Almeida Da Silva PE, Palomino JC. J Antimicrob Chemother. 2011; 66:1417-1430. [PubMed: 21558086] c) Palomino JC, Martin A. Antibiotics. 2014; 3:317-340. [PubMed: 27025748]

6. a) Pavlov V, Xiao Y, Gill R, Dishon A, Kotler M, Willner I. Anal Chem. 2004; 76:2152-2156. [PubMed: 15053684] b) Li T, Wang E, Dong S. J Am Chem Soc. 2009; 131:15082-15083. [PubMed: 19919152] c) Kong DM, Cai LL, Guo JH, Wu J, Shen HX. Biopolymers. 2009; 91:331339. [PubMed: 19137574] d) Nakayama S, Wang J, Sintim HO. Chem Eur J. 2011; 17:5691-5698. [PubMed: 21469226]

7. a) Kolpashchikov DM. J Am Chem Soc. 2008; 130:2934-2935. [PubMed: 18281995] b) Aw KLD, Neo JL, Utamchandani M. Mol BioSyst. 2010; 6:792-794. [PubMed: 20567764] c) Neo JL, Aw KD, Utamchandani M. Analyst. 2011; 136:1569-1572. [PubMed: 21384012]

8. Hooyberghs J, Carlon E. Biosens Bioelectron. 2010; 26:1692-1695. [PubMed: 20719495]

9. Gerasimova YV, Hayson A, Ballantyne J, Kolpashchikov DM. Chem-BioChem. 2010; 11:17621768.

10. Kolpashchikov DM. Chem Rev. 2010; 110:4709-4723. [PubMed: 20583806]

11. Grimes J, Gerasimova YV, Kolpashchikov DM. Angew Chem Int Ed. 2010; 49:8950-8953.Angew Chem. 2010; 122:9134-9137.

12. a) Deng M, Zhang D, Zhou Y, Zhou X. J Am Chem Soc. 2008; 130:13095-13102. [PubMed: 18763776] b) Deng M, Feng S, Luo F, Wang S, Sun X, Zhou X, Zhang XL. J Clin Microbiol. 2012; 50:3443-3450. [PubMed: 22875898] c) Zhu J, Zhang L, Dong S, Wang E. Chem Sci. 2015; 6:4822-4827. [PubMed: 29142717] d) Lu X, Shi X, Wu G, Wu T, Qin R, Wang Y. Sci Rep. 2017; 7:44211. [PubMed: 28287135] 
A
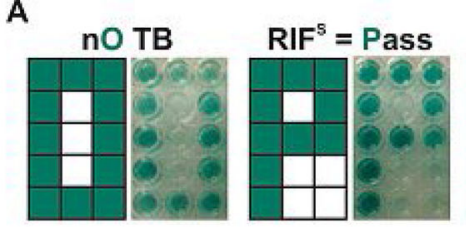

$\mathrm{C}$

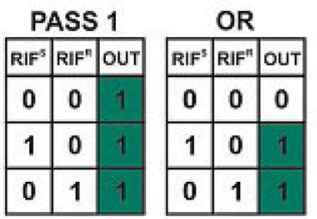

NOR

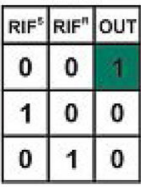

NOT $^{\mathrm{R}}$

RIF $^{3}$ RIF" $^{\text {OUT }}$

\begin{tabular}{l|l|l|l|l}
\hline 0 & 0 \\
\hline & 0 & 1 & 0
\end{tabular}

\begin{tabular}{|l|l|l|}
\hline 1 & 0 & 1 \\
\hline 0 & 1 & 0 \\
\hline
\end{tabular}

B

\begin{tabular}{|c|c|c|}
\hline 1 & 2 & 3 \\
\hline $\begin{array}{c}\text { PASS } 1 \\
1-\end{array}$ & $\begin{array}{l}\text { PASS 1 } \\
1-\end{array}$ & $\begin{array}{c}\text { PASS } \\
1-\end{array}$ \\
\hline $\begin{array}{c}\text { PASS } 1 \\
1-\end{array}$ & $\begin{array}{l}\text { PASS 0 } \\
0-\end{array}$ & $\begin{array}{l}\text { NOT }^{R} \\
\text { RIF }^{2}\end{array}$ \\
\hline $\begin{array}{c}\text { PASS } 1 \\
1-\end{array}$ & $\begin{array}{c}\text { OR } \\
\text { RIF }^{6} \\
\text { RIF }^{-1}-\end{array}$ & $\begin{array}{l}\text { NOT }^{n} \\
\text { RIF }^{\mathrm{R}}-\end{array}$ \\
\hline $\begin{array}{c}\text { PASS } 1 \\
1-\end{array}$ & $\begin{array}{l}\text { PASS 0 } \\
0-\end{array}$ & $\begin{array}{l}\text { NOR } \\
\text { RIF" } \\
\text { RIF" }\end{array}$ \\
\hline $\begin{array}{c}\text { PASS } 1 \\
1-\end{array}$ & $\begin{array}{l}\text { NOR } \\
\text { RIF } \\
\text { RIF' }\end{array}$ & 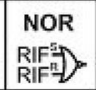 \\
\hline
\end{tabular}

Figure 1.

The design and performance of alphanumerical sensor display. A) Theoretical (left) and experimental (right) observation of the display in the absence of MTC DNA ("no TB") and in the presence of DNA inputs corresponding to MTC with either RIF-sensitive or RIFresistant phenotype ("RIFS" or "RIF",, respectively). PASS 0 gate wells contained just a colorimetric buffer with no gate strands. PW17 at $0.2 \mu \mathrm{M}$ served as PASS 1 gate; OR and NOR strands were at 1 and $0.5 \mu \mathrm{M}$, respectively; and for NOT ${ }^{\mathrm{R}}$ function, $\mathrm{YES}^{\mathrm{S}}$ and NOR strands were at 0.8 and $0.4 \mu \mathrm{M}$, respectively. B) Arrangement of $\mathrm{G}_{4}$ DNA logic gates into a 305 graphical display. The logic gate names and symbols are indicated. The two wells containing a mixture of YES ${ }^{S}$ and NOR gate working in parallel are marked with a symbol for $\mathrm{NOT}^{\mathrm{R}}$ gate, as this combination computes a logic negation of $\mathrm{RIF}^{\mathrm{R}}$ input (for a detailed explanation see the Supporting Information). C) Truth tables for most of the $\mathrm{G}_{4}$ logic gates used in the display. High output is highlighted in green. 


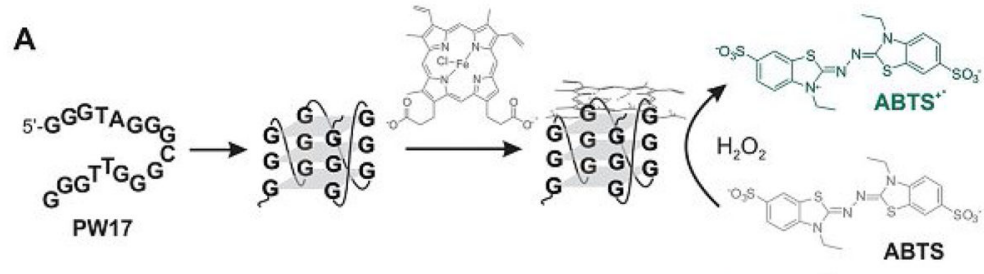

B

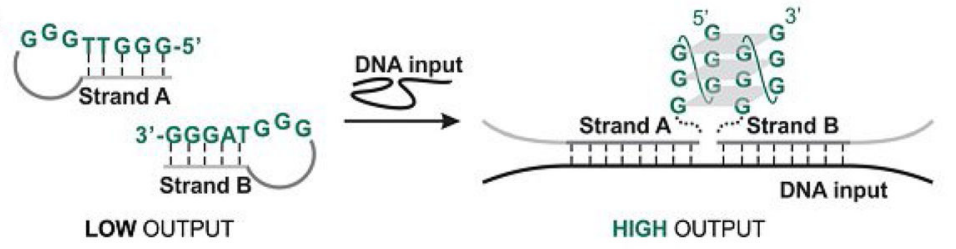

C $\quad a_{G}^{5_{G}^{\prime}} G_{G}^{G^{3}}$

$G(G) G$

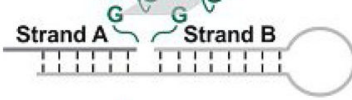

HIGH OUTPUT

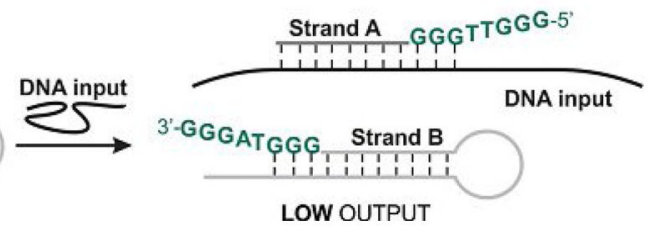

\section{Scheme 1.}

Design of $\mathrm{G}_{4}$-based DNA logic gates with visually detected output. A) PW17 ${ }^{[6]}$ folds into a parallel $\mathrm{G}_{4}$ structure with affinity for hemin. The PW17-hemin complex catalyzes peroxidation of the colorless organic substrate ABTS into the blue-green $\mathrm{ABTS}^{+\cdot}$. PW17 will produce high output independent of the presence of analyte; this corresponds to PASS 1 logic. B) YES and OR gates. Strands A and B of the gate associate into a catalytically active $\mathrm{G}_{4}$ structure ("high output") only in the presence of a specific DNA input. An OR gate targets the input fragment outside an SNS position and thus responds to either RIF ${ }^{\mathrm{S}}$ or $\mathrm{RIF}^{\mathrm{R}}$ input. A YES gate targets SNS-containing input fragments and selectively binds to RIF only. C) $\mathrm{G}_{4}$-based NOR gate. In the absence of a DNA input (either RIF ${ }^{\mathrm{S}}$ or RIF ${ }^{\mathrm{R}}$ ), strands $A$ and $B$ are bound to each other forming an active $G_{4}$ peroxidase structure ("high output"). The input binds to strand $\mathrm{A}$, thus displacing it from the complex and turning off the peroxidase activity ("low output"). 